\title{
State-of-Art Review on Assessment of Surface water and Groundwater in a Sub-watershed Using ArcSWAT
}

\author{
Brema J, Minnu K Benny
}

\begin{abstract}
For the development and sustenance of life in cities and villages, water of sufficient quantity and quality is an essential resource not only for agriculture, industry, and tourism. Water has various sources such as rainwater, surfacewater and groundwater etc. This resource is distributed in time and space with lot of variations. It is necessary that the hydrological cycle is maintained with proper balance in order to sustain the environment. The water resources management is gaining importance and is carried out at watershed or drainage basin level. A watershed or drainage basin refers to an area providing runoff of streamflow to the mainstream of a river and its tributaries. Quantitative analysis of watershed network within a basin can highlight the predominant processes that is essential for planning watershed management, runoff estimation, floods etc. The integration between GIS, and physiographic features of basin to assess runoff and groundwater has been continually upgraded and widespread in recent years, as there is a increased availability of spatial databases and GIS softwares. This paper presents a thorough study of various approaches for morphometric analysis, sufacewater and groundwater assessment in a basin or watershed.
\end{abstract}

Index Terms - Morphometric, Surfacewater, Groundwater, Stream, Aquifer

\section{INTRODUCTION}

The amount of water available is decreasing with time. So we need to have a study on the amount of water present in today's time. This will help us to preserve the present sources. The total amount of water present in a watershed can be divided into surface water and groundwater. Surface water includes those which are flowing as runoff, stream flow etc., while groundwater includes those which are stored in the aquifer. Therefore, in order to quantify the water, we need to study about the morphometry of the watershed which includes features like stream length, stream order etc. and the aquifer characteristics like the transmissivity; water yield etc. Based on the characteristics of the streams and aquifer characteristics the groundwater and surface water can be quantified.

\section{MORPHOMETRIC ANALYSIS}

The watershed delineation using LiDAR elevation data in the Geoinformatics and remote sensing field is a new

Manuscript revised June 9, 2019 and published on July 10, 2019

J.Brema, Professor, Department of Civil Engineering, Karunya Institute of Technology and Science, Coimbatore, India

Minnu K Benny, PG Student, Department of Civil Engineering, Karunya Institute of Technology and Sciences, Coimbatore, India method which will work in mobiles. (Aaron et.al 2016). When the existing large scale algorithms are applied to micro topographic DEMs, the results can be varied with respect to direct observations. Even though local drainages are affected in this method but suitable methods have been developed to overcome this change. GIS techniques can be applied for the delineation of the watershed in plain polders using SWAT model (Baolin et.al 2011). New methods for watershed delineation have been adopted using ArcSWAT tool where DEM is only required and all the other steps can be subsequently done with less time. Under the GIS environment, satellite data can be used for obtaining the hypsometric curve and hypsometric integral. (Sudhir et al 2016). The result shows that the HI value ranges from 0.36 to 0.89 , which indicates that the geomorphic development is from youth to mature stage. It helps in measuring the watershed health; represent the form, its evolution, and morphology of the river basin. ArcGIS extension tool will automatically generate the values for the hypsometric curve and the manual calculations can be omitted ( $\mathrm{Pe}^{\prime}$ rez-Pen et.al 2009). Multiple hypsometric curves are generated from DEM models. The hypsometric curves are generated by integer data-model properties of ArcGIS and summations algorithms which is an easy method. For soil protection and flood control measures, morphometric parameters can be derived using cartosat-1 data (Apurna et.al 2015). With the help of ERDAS and ArcGIS software tools, several characteristics of the drainage basin are analysed scientifically. With respect to hydrologic values, the morphometric characteristics of the subwatershed were derived. The different linear and areal aspects of Bhadra river basin (Jyoti et.al 2015) were studied using ArcGIS software. It showed dendritic type drainage from first to seventh orders. Using ArcGIS software, the elongation ratio was found out which showed less value. The morphometric analysis of Kallada and Pallikkal river basins of Kerala includes linear and areal aspects of two river basins (Nimiya et.al 2014). Various linear aspects of morphometry such as stream order, stream length ratio, bifurcation ratio etc. and areal aspects like drainage density, shape factor, form factor, elongation ratio, circulatory ratio, length of overland flow etc. were calculated for both the river basins. The measurement and analysis for linear, areal and relief aspects of the two sub-catchments of Sukri river catchments in Rajasthan (Narender 2013) were done using remote sensing and GIS. At the sub-catchment levels, a good relationship was found between the morphometric parameters and the terrain characteristics. Using 1:50,000 scale SOI toposheets, the watersheds were delineated using remote sensing data in the Pavagada area of Tumkur district, South India (Govindaiah et.al 2004). It showed dendritic to sub dendritic pattern in the drainage network whereas the 
streams ranged from fourth to fifth order. Drainage density varies from 1.55 to $2.16 \mathrm{~km} / \mathrm{km}^{2}$ by which it showed very coarse to coarse drainage texture along with a relief ratio which ranges from 0.006 to 0.021 . Various thematic maps of the study area such as land use/land cover, soil, drainage, slope and contour were prepared to assess morphometric characteristics of Shetrunji River basin (Harji et.al 2013). The mean bifurcation ratio was found as 4.51 with a variation of 1.8 to 4 for the 17 watersheds. In the morphometric analysis of Rora watershed in Dindori district in Madhya Pradesh using GIS technique (Sandeep et.al 2017), it was observed that the drainage pattern of the watershed is the dendritic type. Linear aspects of morphometric analysis describe the drainage basin is not influenced by geologic structure. In the morphometric analysis, it is observed that the drainage pattern of the watershed is the dendritic type which indicates homogeneity in structure and lack of structural control. The morphometric parameters and hydrological changes in Parbati River Basin in Himachal Pradesh (Sumantra 2016) used remote sensing and GIS for the morphometric studies along with Strahler's method of stream ordering. It was found to be a 6th order basin and first orders were the most dominating ones. The study revealed that basin has an oval to a less elongated shape which was because of the steep ground slopes. The tendency to decrease the average annual and seasonal discharge in the Parbati River was found to be because of climatic variability and anthropogenic causes. The prioritization of sub-watersheds in Piperiya watershed, India was based on morphometric analysis using spatial mapping (Surendra et.al 2014). Generation of drainage lines and assessment of the relative parameters such as stream order, form factor, circulatory ratio, elongation ratio, bifurcation ratio etc in this study was calculated using remote sensing and GIS. The analysis revealed that stream order varied from 1 to 5 . For watershed delineation studies and for morphometric analysis, remote sensing (RS) and geographical information system (GIS) have proved to be an effective tool. The drainage basin is of the 5th order and the drainage density value is low which is due to the permeable subsoil and thick vegetation. This is because of the wide range of data availability at various resolutions for watersheds (Brema et.al 2014). Remote sensing and GIS was used to understand the geometry of one of the watersheds of Harike Lake, Punjab (Ghnabi et.al 2018) with much emphases on the evaluation of the morphometric parameters included linear, relief and aerial parameters The morphometric analysis revealed that that the watershed under study has 5th stream order drainage basin. There are three categories of sub-watersheds which are high, medium and low which is based on the priority for conservation of natural resources (Shailesh 2010). Two out of seven watersheds namely SW1 and SW6 were categorized as a high priority, whereas SW7 has been categorized as medium priority. To delineate watersheds and to extract the drainage networks along with the thematic maps such as elevation and slope, the DEM were used (Rajendra 2016). The mathematical calculations of morphometric parameters like stream order, bifurcation ratio, drainage density and so on of valheri river basin in nandurbar district using GIS techniques (Subhash 2011). The main objective of the study was to analyse the morphometry of the basin. This helped in making decisions related to flood and management of water resources.

\section{SURFACEWATER ESTIMATION}

The capability of the SWAT model for simulating streamflow in a tropical watershed - upper Kuantan river basin was tested (Faisal et.al 2015). For model evaluation, two statistical metrics called the coefficient of determination (R2) and nash-sutcliffe efficiency index (NSI). The calibration result showed that both the observed and simulated monthly stream flow are nearly the same. The uncertainty analysis, calibration and validation of the SWAT model were conducted using ArcSWAT and ArcGIS combined with Sequential Uncertainty Fitting-2 algorithms in an ungauged catchment of Tonlesap lake basin in Cambodia (Chantha et.al 2018). The results for the daily simulation showed good values. The monthly time series results were improved and acceptable for the stream flow. In both the calibration and validation periods, the variability of daily and monthly streamflow hydrograph time series was captured well by the SWAT model. The estimation of the water balance component in Rangmati River basin using swat model included total $518 \mathrm{~km}^{2}$ area of river basin which was subdivided into 7 subwatershed and 230 hydrologic response units (HRUs) (Hina et.al 2017). The average of mean seasonal and annual water balance component showed that seasonal rainfall, seasonal runoff, seasonal groundwater recharge and seasonal groundwater recharge was found increasing at $75.65 \mathrm{~mm} /$ decade, $47.32 \mathrm{~mm} /$ decade, 10.91 $\mathrm{mm} /$ decade and $12.10 \mathrm{~mm} /$ decade respectively. To find the total availability of water in the basin and to create a hydrologic model using the SWAT model, rainfall-runoff estimation was done for Holetta River (Assefa et.al 2017). Based on the classification in the SWAT model, the entire watershed was divided into 6 sub-basins and 33 hydrological response units (HRUs). Simulation of streamflow using SWAT tool in upper Ayeyarwady basin focuses on the stream flow estimation (Nilar et.al 2016). The coefficient of determination (R2) and nash sutcliffe Efficiency (NS) values for both the calibration and validation showed good results. The estimation of water balance components of Shaya mountainous watershed, southeastern Ethiopia (Shawul et.al 2016) was used for studying about the patterns and related trends in the observed flow which can be used for the future generations. Mean monthly and annual water yield simulated with the calibrated model were found to be $25.8 \mathrm{~mm}$ and $309.0 \mathrm{~mm}$, respectively. Using high-resolution gridded precipitation data with $3 \mathrm{~km}$ resolutions based on the spatial 15 interpolations of gauged stations, the runoff simulation of the upper Heihe river basin (Hongwei et.al 2016) was done. With the exact representation of the sub-basin precipitation input data, the SWAT model showed a good comparison with the monthly runoff simulation with the observed data in three stations. There was an acceptable agreement between simulated and observed data which was verified to obtain adequate values for the watershed in the tropical region in North Vietnam by modelling surface runoff and evapotranspiration (Hong et.al 2015). A good correlation existed between discharges produced by the models. Streamflow is the most important factor for accessing water 
availability at the river basin level in Seonath river basin using the SWAT model (Mani et.al 2018). The runoff is generated using meteorological data for 35 years using the observed flow at the basin outlet. Poor correlation existed between the observed and modelled flow. Different soil parameters in agricultural conditions in ungauged watersheds are estimated by Soil and water assessment tool (SWAT) which is a distributed model physically and GIUH (Irshada et.al 2016). The watershed process can be simulated using sub-daily rainfall by the new provision in SWAT. And this can be used for event modelling, though the model is generally meant for continuous modelling. The surface runoff for ungauged basins can be predicted by using GIUH. From this study, it was also seen that the GIUH method are marginally better than that from the SWAT model. For hydrological modelling, geographic information systems (GIS) offer many new methodologies land one among them is conceptual rainfall-runoff modelling (Schumann et.al 2000). Components can be combined and used in hydrologic modelling namely, between surface return and flow, flow and filtration. Temperature and rainfall time series trend analysis along with variability for the Woleka sub-basin was studied. (Amogne et.al 2018). This was used to find the change in rainfall and temperature using data obtained from global precipitation and climate such as gridded monthly precipitation data. It was seen that the variability in rainfall was increasing with the drought pattern and rainfall was also decreasing annually. The analysis was done in the hydrological subbasins in western Iran to find the averages in monthly and annual rainfall using time series method. (Mahsa et.al 2016). The changes in the hydrologic time series data such as rainfall and climatic data were used for trend analysis in the Kelantan river basin (Asmat et.al 2016). This study was done to spatially map the rainfall trend using results obtained from mann-kendall test and to quantify the changes in the trend of rainfall with the help of statistical tests on the basis of monthly, annual and seasonal changes. The IDF curve for the different return periods has been developed by Gumbel distribution Type I method. It is showed that as the duration increases, the rainfall intensity decreases.A good fitness is observed from the probability analysis by linear method and the regression values vary from 0.7422 to 0.753 for various return periods (Anie et. al. 2018). The rainfall data in the past can be used to analyse the variability of rainfall in Peninsular Malaysia for the years 1948 to 2002 (Mohmadisa 2012). The major factor used was the seasonal changes which play an important role in the water yield. The decline in the annual rainfall yield also led to the lowering of the water table in some parts of Saharanpur district of Uttar Pradesh (Kumar et.al 2012). This study examines the general rainfall pattern in Saharanpur district of Uttar Pradesh, using monthly rainfall data for 30 years (1982-2011). This has an implication in the digging of wells, construction of boreholes, and other water resource development projects that depend on water from groundwater sources.

\section{GROUNDWATER ESTIMATION}

With remote sensing and modelling, the water balance components were computed to obtain the net recharge in the hakra branch canal system of Pakistan (Jehanzeb et.al 2016). Using SWAT it was calibrated for the period of two years from 2006-08 and validated for the period of two years from 2009-11 and both of these obtained good results. The groundwater investigation was done using various tests like step-drawdown, well logs etc. with the help of hydrogeochemical data in the west of Qena area, Egypt (Fathy et.al 2018). This was done to characterize hydrogeological conditions and was found that the specific capacity values were varied indicating the wells have been designed and developed properly. The spatial distribution of groundwater can be done using the recharge rates through the rain falling in the far-north region of Cameroon (Ambe et.al 2016). A groundwater recharge modelling was done using GROWA which showed a good agreement with existing rates of assessments in the areas of study. Based on the relations of hydrologic and meteorological variables, the historical groundwater levels were accessed in the U.S. glacial aquifer. (Dudley et.al.2018) Groundwater levels were modelled according to the data in most areas. From the historical rainfall records groundwater recharge quantification and salinity mapping was done in the Ramsar-listed Verlorenvlei catchment, South Africa (Eilers et.al 2017). The results were compared to longer-term rainfall values to predict future availability in groundwater. For estimating the specific yield and recharge, a water balance model was in data-scarce hard-rock regions (Deepesh et.al 2015). A new method was used which combines both double water-table fluctuation technique and geographical information system for estimating the specific yield and distributed recharge. By means of hydrogeological data, this study was used to identify those locations where aquifer storage and recovery can be carried out in Texas (Benjamin et.al 2017). This is a state were droughts are very frequent along with storms which are due to high evaporation rates. To find the feasibility in implementing ASR system many indexes were mapped using GIS like hydraulic gradient, well density etc. The spatial distribution of groundwater potential zones was done using geological exploration in Juye Coalfield, Shangdong, China (Huiyong et.al 2017). Various parameters like fault length density, frequency, variation coefficient etc. were used for computation of geological, tectonic and lithological composition index. The hydrodynamic simulation was performed to compute the water surface profiles for floods of different return periods of lower Ambika river of Navsari city (Darshan et.al 2017). The objective of the study is to find the stability of a segment of lower Ambica river basin by computing its storage in response to discharge (flood magnitude) and slope. The mean annual recharge can be computed using mean annual precipitation by means of empirical equations the ratio of in semi-arid basins (Hoori et.al 2016). The ratio of winter vs. summer recharge can be obtained from isotopic data in the upper San Pedro river basin, Arizona. A multi-criteria decision analysis was used in ArcGIS to find suitable areas to use the ASR technology to reduce flooding and improve the accessibility to water during the dry season (Benjamin et.al 2017). The artificial groundwater storage system in northern Ghana has high potential based on other conditions. To estimate the hydraulic conductivity from the Waxman-Smits model many parameters were used like porosity, hydraulic properties etc. (George et.al 2017). This can be used economically from surface resistivity data in many locations 
with suitable information in the boreholes. Estimation of shallow groundwater recharge at small scale using a SWAT model requires inputs which can be prepared using satellite images. (Giheung 2006). The data includes land use maps, rainfall, soil maps etc. this was calibrated based on four years of daily streamflow data using shuffled complex evolution global optimization method.

\section{CONCLUSIONS}

Based on the study, it can be concluded that the surface and groundwater assessment can be done using ArcSWAT but requires a lot of data sets like daily rainfall, temperature, solar radiation, wind speed, soil map etc. The calibration and validation will show good agreements with the results obtained. For better results, it should be done for a good set of years which can lead to accurate values. ArcGIS serves as a good platform for preparation of inputs for the analysis to be done in ArcSWAT.

\section{REFERENCES}

[1] Aaron Ault, Dennis Buckmaster, Samuel Noel, "Watershed Delineation in the Field: A New Approach for Mobile Applications Using LiDAR Elevation Data," Annual International Meeting Paper, 2016.

[2] A.E.Giheungand, F.S.Akpan, "Assessment of spatial distribution of porosity and aquifer geohydraulic parameters in parts of the Tertiary -Quaternary hydrogeo resource of south-eastern Nigeria,"NRIAG Journal of Astronomy and Geophysics, Vol. Issue 2. pp. 422 - 433, 2017.

[3] A.H.Schumann, G.A.Schultz, R.Funkeb, "Application of a Geographic Information System for Cconceptual Rainfall Runoff Modelling," Journal of Hydrology, Vol. 240, pp.45-61, 2000.

[4] Amogne Asfaw, Belay Simane,"Variability and Time Series Trend Analysis of Rainfall and Temperature in North Central Ethiopia: A Case Study in Woleka Sub-basin," Weather and Climate Extremes, Vol.19, pp.29-41,2018.

[5] Ambe Emmanuel Cheoa, Hans-Jürgen Voigta, Frank Wendland, "Modelling groundwater recharge through rainfall in the Far-North region of Cameroon," Groundwater for Sustainable Development, Vol.5, pp.118-130, 2017.

[6] Asmat Amis, Nor Aizam Adnan, "Rainfall Trend Analysis and Geospatial Mapping of the Kelantan River Basin,"Journal of Geographic Information System, Vol.8, pp.20-27, 2016.

[7] Assefa M. Melesse, DerejeHailu, Mahtsente Tibebe,'Rainfall-runoff relation and runoff estimation for Holetta River, Awash subbasin, Ethiopia using SWAT model," International Journal of Water Resources and Environmental Engineering, Vol. 9, Issue.5, pp.102-112, 2011.

[8] Baolin Su, Junying Yuan, YunxiangLuo, “GIS Techniques for Watershed Delineation of SWAT Model in Plain Polders," Procedia Environmental Sciences, Vol.10, pp. 2050 - 2057, 2010.
[9] Benjamin Nguyen, Martin Kappas, "Modeling Surface Runoff and Evapotranspiration using SWAT and BEACH for a Tropical Watershed in North Vietnam, Compared to MODIS Products," International Journal of Advanced Remote Sensing and GIS, Vol.4, Issue 1, pp. 2320 - 0243, 2015.

[10] Benjamin Ghansah, Pa Kofi Osei-Owusu, “Assessing Land Suitability for Aquifer Storage and Recharge in Northern Ghana using Remote Sensing and GIS Multi-criteria Decision Analysis Technique," Model Earth System Environment, Vol.3, Issue 4, pp. 1383-1393, 2017.

[11] J. Brema, Daina Souza Lima, "Morpohometric Analysis of Noyyal Sub-Watershed," International Symposium on Integrated Water Resources Management (IWRM), 2014.

[12] Chantha Oeurng, Raksmy Ang, "Simulating Stream flow in an ungauged catchment of Tonlesaplake basin in Cambodia using (SWAT) Model," Water Science, Vol.32, pp.89-101, 2018.

[13] C.P.Kumar, GopalKrishan, M.S.Rao, Pankaj Garg, "Rainfall Trend Analysis in Saharanpur District of Uttar Pradesh-Agricultural Context," 28th National Convention of Civil Engineers \& National Seminar on Role of Infrastructure on Sustainable Development, pp. $691-698,2012$.

[14] Darshan Mehta, S.M.Yadav,"Assessment of Urban Flood Area using HEC-RAS: A Case study of Ambika River" Hydro- International, 2017.

[15] Deepesh Machiwal, Madan K. Jha, "GIS-based Water Balance Modelling for Estimating Regional Specific Yield and Distributed Recharge in Data-scarce Hard-rock Regions," Journal of Hydro-Environment Research, Vol. 9, Issue 4, pp. 554-568, 2015.

[16] Dudley, M.O.Dinka, "Calibration and validation of SWAT model and estimation of water balance components of Shaya mountainous watershed, Southeastern Ethiopia," Hydrological Earth System Sciences, Vol.10, pp.13955-13978, 2016.

[17] A.Eilers, J.Miller, A.Watson A, N.Sigidi, "Groundwater Recharge Quantification from Historical Rainfall Records and Salinity Profiling in the RAMSAR listed Verlorenvlei Catchment, South Africa," Procedia Earth and Planetary Science, Vol.17, pp.586 - 589, 2017.

[18] Faisal Mohammed, Liew Juneng, Nor Faiza Rahman, Fredolin Tangang, "Simulation of Upper Kuantan River Basin Stream flow Using SWAT Model," AIP Conference Proceedings, 2015

(19) Fathy Rochdi, Hassane Brirhet, Mourad Khatati, Namira El, Yassine Bouslihim, Hydrologic Modeling Using SWAT and GIS, Application to Subwatershed Bab-Merzouka (Sebou, Morocco)," Journal of Geographic Information System, Vol.8, pp. 20-27, 2016.

[20] R.W.Dudley, G.A.Hodgkins, M.G.Nielsen, S.L.Qi, "Estimating Historical Groundwater Levels Based on Relations with Hydrologic and Meteorological Variables in the U.S. Glacial Aquifer System", Journal of Hydrology, Vol.562, pp.530-543, 2018.

[21] George Gemitzi, Hoori Ajami, "Developing Empirical Monthly Groundwater Recharge Equations Based on Modelling and Remote Sensing Data - Modelling Future 
Groundwater Recharge to Predict Potential Climate Change Impacts," Journal of Hydrology, Vol.546, pp.1-13, 2017.

[22] GhNabi Najar, Puneet Pandey, "Drainage Morphometric Analysis of Watershed Basin of River Beas at HarikePattan, Punjab-Using Remote Sensing and GIS Approach", International journal on Advance Research in Science and Engineering, Vol.7, Issue 4. pp.641-653, 2018.

[23] Harji rank, Hina Bhatu, "Estimating the Water Balance Component in Rangmati River Basin using Swat Model," International Journal of Agricultural Science and Research, Vol.7, Issue.4, pp.547-554, 2017.

[24] H.D.Apurna, S.S.Wandre, "Assessment of Morphometric Characteristics of Shetrunji River Basin using Remote Sensing and Geographical Information System (GIS)," African Journal of Agricultural Research, Vol.8, Issue 18, pp.2003-2015, 2013.

[25] Hina Chopra, Raman Deep Dhiman, "Morphometric analysis of sub-watersheds in Gurdaspur district, Punjab using Remote sensing and GIS techniques," Journal of the Indian Society of Remote Sensing, Vol. 33. 33, pp.531, 2005.

[26] Hongwei Ruan, Songbing Zou, "Runoff simulation by SWAT model using high-resolution gridded precipitation in the upper Heihe River Basin, Northeastern Tibetan Plateau", Hydrological Earth System Science Discussions, Vol.10, 2016.

[27] Hoori Ajami, Thomas Meixner, "Seasonalizing Mountain System Recharge in Semi-Arid Basins-Climate Change Impacts," Groundwater 2012, Vol.50(4), pp.585-97, 2012.

[28] Hoori R. Millera, Zhuping Sheng,": Assessing Aquifer Storage and Recovery Feasibility in the Gulf Coastal Plains of Texas. Journal of Hydrology: Regional Studies, 2017,

[29] Huiyong Yin, Yongli Shi,“A GIS-Based Model of Potential Groundwater Yield Zonation for a Sandstone Aquifer in the Juye Coalfield, Shangdong, China," Journal of Hydrology, Vol.557, pp.434-447, 2017.

[30] Irshada Iskendera, N.Sajikumar, "Evaluation of Surface Runoff Estimation in Ungauged Watersheds using SWAT and GIUH," Procedia Technology, Vol.24, pp.109-115, 2015.

[31] Jehanzeb Muhammad, Muhammad Shafeeque, "Quantification of groundwater abstraction using swat model in hakra branch canal system of Pakistan," Pak. J. Agri. Sci., Vol. 53, Issue.1, pp.249-255, 2016.

[32] J.V.Pe'rez-Peña, "CalHypso: An ArcGIS extension to calculate hypsometric curves and their statistical moments, Applications to drainage basin analysis in SE Spain”, Computers \& Geosciences, Vol.35, pp.1214-1223, 2009.

[33] JyotiSarup, Vishnu Dayal, "Quantitative Morphometric Analysis of Bhadar River Basin, India using ASTER (GDEM) Data and GIS", International Journal of Advanced Remote Sensing and GIS, Vol.4, Issue 1, pp.1204-1213, 2015.

[34] Mahsa Farhangiand, MajidKholghi, "Rainfall Trend Analysis of Hydrological Sub basins in Western Iran,"
Journal of Irrigation and Drainage ASCE, Vol.142, Issue 10, 2015.

[35] Mani Kant Verma, Sabyasachi Swain,"Stream flow Estimation Using SWAT Model Over Seonath River Basin, Chhattisgarh India," Hydrologic Modelling, Vol.81, pp.659-665, 2018.

[36] Mohmadisa Hashim, "Rainfall Trend Analysis Using 50 Years Historical Data in Newly Developed Catchment in Peninsular Malaysia", Middle East Journal of Scientific Research, Vol.11, Issue 5, pp.668-673, 2012.

[37] Nimiya Baby, Priya Philip, "Morphometric Analysis of Kallada and Pallikkal River Basins of Kerala", Integrated Water Resources Management (IWRM), 2014.

[38] Narender Kumar, "Morphometric analysis of river catchments using remote sensing and GIS ( A case study of Sukri river, Rajasthan)," International Journal of Scientific and Research Publications, Vol.3, Issue. 6, pp.1-6, 2013.

[39] Nilar Aye, Wai Aung, "Simulation of Stream Flow Using Soil and Water Assessment Tool (SWAT) in Upper Ayeyarwady Basin," International Journal of Research in Chemical, Metallurgical and Civil Engineering, Vol.3, Issue. 2, pp.2349-1450, 2016.

[40] K.R.Sandeep, Shashikant, "Morphometric Analysis of Rora Watershed in Dindori District M.P. using GIS Technique," National initiative on Climate Resilient Agriculture, 2017.

[41] S.Govindaiah, S.Srinivasa Vittala, "Morphometric analysis of sub-watersheds in the Pavagada area of Tumkur district, south India using remote sensing and GIS techniques," Journal of the Indian Society of Remote Sensing, Vol. 32, pp.351, 2004.

[42] Shailesh Kumar, "Morphometric Analysis and Prioritization of Watershed using GIS," Journal of Indian Water Resources, Vol.32, No.10, pp. 33-39, 2010.

[43] Santosh Pingale, Harish Chandra, H.C.Sharma, S.Sangita Mishra, "Morphometric Analysis of Maun Watershed in Tehri-Garhwal District of Uttarakhand Using GIS," International Journal Of Geomatics And Geosciences, Vol. 3, No.2, pp.373 - 387, 2012.

[44] Subash Lal Kansal, Surendra Kumar Chandniha, "Prioritization of sub-watersheds based on morphometric analysis using geospatial technique in Piperiya watershed, India," Applied Water Science, Vol. 7, Issue 1, pp.329-338, 2014.

[45] Sudhir Kumar Singh, Vimla Singh, "Hypsometric Analysis Using Microwave Satellite Data and GIS of Naina-Gorma River Basin (Rewa district, Madhya Pradesh, India," Water Conservation Science and Engineering, Vol.3, Issue 4, pp.221-234, 2016.

[46] Sumantra Sarathi Biswas, "Analysis of GIS Based Morphometric Parameters and Hydrological Changes in Parbati River Basin, Himachal Pradesh, India," Journal of Geography \& Natural Disasters, Vol.6, pp.175, 2016.

[47] S.Anie John, J.Brema, "Analysis of Rainfall by Intensity duration- Frequency (IDF) Curves for Vamanapuram River Basin, Kerala," International 
International Journal of Research in Advent Technology, Vol.7, No.6, June 2019

E-ISSN: 2321-9637

Available online at www.ijrat.org

Journal of Civil Engineering And Technology, Vol. 9, Issue 7, pp. 403-411, 2018.

\section{AUTHORS PROFILE}

Brema.J has an academic background with B.Tech in Civil Engineering, Postgraduate degree in Water Resources and Doctoral degree in Civil Engineering (Specialization in Water Resources). Apart from teaching, she has carried out research work and have published 90 research papers in national and international journals and conferences. Currently she is guiding 6 doctoral students and Membership as Fellow of Institution of Engineers, Indian Society of Technical education and Indian Water Resources Society. She has published a book on Rainfall Variation with reference to Landuse changeNoyyal Basin, Lambert Academic Publishing in the year 2017.

Minnu K.Benny is a post graduate student in the discipline: Environmental and Water Resources Engineering. She has expertise in surface water modeling using ArcSWAT and Hec-Ras softwares. 